\title{
EL CONCEPTO DE TOTALITARISMO EN EL DEBATE POLÍTICO ITALIANO: UNA HISTORIA PARTICULAR $(1923-1994)^{1}$
}

\author{
The Concept of Totalitarianism in Italian Political \\ Discourse: A Particular History (1923-1994)
}

\author{
ANDREA DONOFRIO \\ JUAN FRANCISCO FUENTES \\ Universidad Complutense de Madrid
}

Revista de Estudios Políticos

ISSN-L 0048-7694, núm. 171, Madrid, enero/marzo (2016), pp. 13-40 http://dx.doi.org/10.18042/cepc/rep.171.01

Cómo citar/Citation

Donofrio, A. y Fuentes, J. F. (2016). El concepto de totalitarismo en el debate político italiano: una historia particular (1923-1994).

Revista de Estudios Políticos, 171, 13-40

doi: http://dx.doi.org/10.18042/cepc/rep.171.01

\section{Resumen}

Este artículo analiza la evolución del concepto de totalitarismo en Italia desde su aparición en 1923. Desde aquel momento, el concepto recorrió distintas etapas históricas marcadas por el contexto nacional e internacional, fundamentalmente relacionadas con el fascismo hasta 1945 y posteriormente con la guerra fría y su variable intensidad. Sorprende que Italia se mantuviera por lo general tan alejada del llamado "paradigma totalitario", es decir, de los usos y significados predominantes en el mundo occidental, sobre todo en la guerra fría. El artículo muestra la relativa singularidad del concepto en el discurso político italiano a lo largo de su recorrido histórico y las claves que explican esta «historia particular».

1 Este artículo forma parte de la investigación llevada a cabo por J. F. Fuentes en 2014 como Visiting Senior Fellow en el IDEAS Centre de la London School of Economics, durante una estancia financiada con una beca de movilidad en centros extranjeros para profesores e investigadores séniores concedida por el Ministerio de Educación, Cultura y Deporte en el marco del Plan Estatal de Investigación Científica y Técnica y de Innovación 2013-2016. 


\section{Palabras clave}

Totalitarismo; Guerra Fría; fascismo; comunismo; nazismo.

\section{Abstract}

This article studies the evolution of the concept of totalitarianism in Italy from its appearance in 1923. From that moment on, the concept went over different historical periods marked by the national as well as the international context, mainly related to fascism until 1945 and after with the cold war and its changing intensity. It is surprising that Italy stayed in general so far from the so called «totalitarian paradigm», i.e., the leading uses and meanings in the Western world, particularly during the Cold War. The article shows the relative uniqueness of the concept in the Italian political discourse throughout its historical evolution and the keys that explain this "particular history».

\section{Key words}

Totalitarianism; Cold War; fascism; communism; nazism. 


\section{SUMARIO}

I. DE LA GUERRA TOTAL AL ESTADO TOTALITARIO. II. LA GUERRA FRÍA: UN NUEVO PARADIGMA. III. DISTENSIÓN (MA NON TROPPO). IV. ÉRASE UNA VEZ EL GRAN PARTIDO COMUNISTA. V. CONCLUSIONES. BIBLIOGRAFIA.

\section{DE LA GUERRA TOTAL AL ESTADO TOTALITARIO}

Se ha atribuido a Lenin la creación en 1917 del primer Estado totalitario de la historia (Todorov, 2002: 78), pese a que el término totalitario no fue acuñado hasta seis años después. Es difícil no compartir esta idea si se aplica al régimen bolchevique nacido tras la Revolución de Octubre los criterios más comunes en la definición del totalitarismo: partido único, culto a la personalidad, uso sistemático del terror, fuerte estatalización de la vida pública y privada, policía política y la creación del «hombre nuevo» como objetivo último de una suerte de revolución antropológica que legitimaría los métodos coercitivos del Estado total. Este último sería a su vez la expresión política de la movilización general puesta en marcha en 1914 con la Primera Guerra Mundial, que obligaría a una completa reestructuración de los recursos y servicios estratégicos de un país — los transportes, por ejemplo-, centralizados y dirigidos por el Estado. Pero mientras ese Estado total en ciernes fue sólo, como la economía de guerra, una solución de emergencia frente a las nuevas necesidades de la guerra total, los regímenes totalitarios surgidos poco después aspiraron a ser la alternativa histórica ante el supuesto fracaso del Estado liberal.

La idea de que una nueva forma de guerra requería una concepción distinta del Estado aparecía ya esbozada en el libro que el escritor conservador Léon Daudet publicó en 1918, poco antes del final del conflicto, con el título de La guerre totale. Al definir este fenómeno como «l'extension de la lutte $[\ldots]$ aux domaines politique, économique, commercial, industriel, intellectuel, juridique et financier» (Daudet, 1918: 8), el autor estaba sugiriendo ya la evolución inexorable hacia un sistema que concentrara todos los resortes del poder y los pusiera al servicio de la victoria sobre el enemigo, tal vez incluso más allá de la paz. Si la guerre totale era el desencadenante de ese nuevo sistema, parecía lógico que el Estado resultante fuera igualmente calificado de total. El concepto, sin embargo, no se puso en circulación hasta 1931, con la publicación en Alemania del artículo de Carl Schmitt «El giro 
hacia el Estado total». Tanto en este texto como en otros inmediatamente posteriores, Schmitt situaba en la Gran Guerra la crisis definitiva del Estado liberal, cuyo "normativismo degenerado» le impedía hacer frente a los desafíos de un conflicto de proporciones descomunales, que exigía decisiones inmediatas y enérgicas. No es de extrañar que el concepto schmittiano de totale Staat estuviera vagamente inspirado en el libro de Daudet, aunque el jurista y filósofo alemán apenas recordara el nombre del autor (Faye, 1974: 52). Ernest Forsthoff, discípulo suyo, abundó en la misma idea - «El Estado total» (1933) — y Ernest Jünger vio en la «movilización total» de la guerra de 1914 el origen de una nueva civilización, en la que el obrero-soldado cobraría un papel protagonista gracias a la importancia de la tecnología industrial en la guerra de masas (Traverso, 2001: 24-27).

Mientras la expresión Estado total nace en Alemania hacia 1931, el adjetivo totalitario y el sustantivo totalitarismo habían surgido en Italia en los años veinte. Con una u otra denominación, las raíces históricas y etimológicas de estos conceptos eran esencialmente las mismas. El totalitarismo resultaba indisociable de la experiencia de la Gran Guerra, en la que lucharon los fundadores de los principales movimientos totalitarios de entreguerras -empezando por Mussolini y Hitler-, que tuvieron mucho en su origen de grupos de ex combatientes. La creencia de que tras la guerra total vendría un cambio análogo en la forma de gobierno y la subida de Mussolini al poder en octubre de 1922 explican la facilidad con la que totalitario y sus derivados se incorporaron al lenguaje político italiano de la posguerra. El primer uso del adjetivo data de mayo de 1923, cuando, apenas siete meses después de la Marcha sobre Roma, el político liberal Giovanni Amendola acusó al gobierno de Mussolini de estar implantando en Italia un «sistema totalitario» (Amendola, 1923).

La expresión encontró un eco inmediato en el debate político. Solo dos semanas después, el diputado fascista Alfredo Misuri la utilizaba en un discurso parlamentario inusitadamente crítico con un régimen que, en su opinión, se estaba alejando de los verdaderos fundamentos del fascismo. Al denunciar su degeneración en un "sistema ingeniosamente definido como totalitario», asumiendo así un término surgido en medios antifascistas, Misuri sellaba su temprana ruptura con el régimen e iniciaba una larga andadura en las filas de la oposición moderada (AAPP, 29-5-1923: 9466). Otro diputado opositor se refirió en junio de 1923 al peligro que el «sistema totalitario» entrañaba para la limpieza de los procesos electorales (AAPP, 10-6-1923: 10429). En enero del año siguiente, el católico Luigi Sturzo denunciaba en la prensa la «transformación totalitaria» que, bajo el nuevo Estado-partido, estaban experimentando «todas las fuerzas morales, culturales, políticas y religiosas» 
(Sturzo, 1924) ${ }^{2}$. En noviembre de 1923 y en junio de 1925, el propio Amendola insistió en recriminar al fascismo su «espíritu totalitario» y su «voluntad totalitaria», una expresión que Mussolini, respondiendo probablemente al político liberal, hizo suya tan solo una semana después. Ocurrió el 22 de junio de 1925, significativamente a los pocos meses de iniciarse la llamada fase totalitaria del fascismo, cuando en un clima de fuerte radicalización ideológica, reciente aún la asunción de responsabilidades por el asesinato de Matteotti, el Duce reivindicó ante el IV Congreso Nacional del Partido Fascista «nuestra feroz voluntad totalitaria» («la nostra feroce volontà totalitaria»). No cabe duda de que el término se ajustaba a la perfección al objetivo último de Mussolini de transferir, según sus propias palabras, «todo el poder a todo el fascismo» («tutto il potere a tutto il fascismo»). De ahí el interés del régimen en apropiarse de un adjetivo creado por sus adversarios para denigrarlo y de ahí también la respuesta que un responsable del partido, Roberto Davanzati, dirigió en 1926 a quienes les tachaban de totalitarios: «Sí, somos totalitarios [...]. Queremos serlo de la mañana a la noche» (Petersen, 2004: 8). Para entonces, el término había derivado ya en un nuevo ismo político — tal vez el más importante de los que se acuñaron en el siglo xx-, cuyo origen suele atribuirse al escritor socialista Lelio Basso, autor de un artículo publicado en enero de 1925 bajo el seudónimo de Prometeo Filodemo. El «totalitarismo» sería, según sus palabras, el resultado inevitable de la absorción del Estado por un solo partido, erigido en intérprete único de una voluntad nacional supuestamente unánime (Filodemo, 1925).

Hay que decir que, aunque Basso haya pasado a la historia como el creador de la voz totalitarismo (Petersen, 2004: 7; Fuentes, 2006: 199; Falasca-Zamponi, 1997: 27), el término figura ya unos meses antes en el periódico liberal La Stampa al reproducir entrecomillada, en su número del 31 de agosto de 1924, una réplica a las críticas de complicidad con la masonería que desde el fascismo se venían haciendo al Partido Popular: «El Gobierno-partido», respondía un portavoz anónimo de los populares italianos, «se ha inclinado claramente por un despotismo que no es diferente de los demás, salvo por un mayor grado de totalitarismo arrogante» ${ }^{3}$. El concepto, como se ve, estaba

2 Dos años después, Sturzo publicó, ya en el exilio, el libro L'Italie et le fascisme, que, además de dar a conocer al fascismo entre el público francés, ofrecía una definición del sistema totalitario igualmente válida, según él, para el régimen mussoliniano y para el Estado soviético.

3 «Il Governo-partito si a nettamente scoperto per un dispotismo non diverso dagli altri se non per più intensa gradazione di totalitarismo tracotante». Palabras reproducidas por La Stampa, 31 de agosto de 1924, que remite a un colaborador del periódico Il Popolo. 
evolucionando muy deprisa: en apenas unas semanas, desde su primer uso por Amendola en mayo de 1923, el adjetivo había llegado a la prensa y al Parlamento; en poco más de un año, se había convertido en un nuevo ismo político, y, dos años después de su aparición, Mussolini lo había hecho suyo como seña de identidad del movimiento fascista, que reconoció sin complejos su carácter "totalitario», según la vehemente exhortación de Davanzati a sus camaradas: "Aceptadlo con honor y orgullo" (Peterson, 2004: 8). La oposición no dejó por ello de esgrimirlo para descalificar al régimen. Su papel en el debate político italiano a partir de 1923 resulta, en ese sentido, doblemente paradójico. Lo es sin duda el hecho de que un término creado para resaltar los peores instintos del fascismo fuera utilizado por este último para definir y reivindicar su proyecto, pero sorprende también su permanencia en el lenguaje de la oposición, pese al empeño fascista en apropiarse de su significado y la neutralización, por tanto, del valor derogatorio que le habían atribuido sus creadores. Lejos de todo consenso lingüístico entre los dos sectores antagónicos de la política italiana, la historia del término hasta el final de la Segunda Guerra Mundial estaría marcada por una polarización extrema de su significado, positivo para el fascismo e inequívocamente negativo para sus detractores. Entre estos últimos destacan aquellos que militaban en la oposición liberal y católica, aunque el órgano comunista L'Unità lo utilizará también de vez en cuando desde 1924, por ejemplo para denunciar los abusos del «sistema totalitario" —ni mayoritario ni proporcional — mediante el cual se habían celebrado las elecciones legislativas de $1924^{4}$.

En cambio, se aprecia una cierta semejanza en su utilización por Antonio Gramsci en sus Cuadernos de la cárcel a principios de los años treinta y por Mussolini y Giovanni Gentile en la voz «Fascismo», publicada en 1932 en la Enciclopedia italiana, en la que se afirma categóricamente que «el fascismo es totalitario" y se distingue entre un Estado policial, que los autores repudian, y lo que ellos llaman gobernar «totalitariamente una nación». En el uso muy esporádico que Gramsci hace del concepto, totalitario reviste un carácter entre banal y descriptivo, en todo caso nunca derogatorio, y siempre bajo la influencia - como en el caso de Mussolini y Gentile- de la idea hegeliana de totalidad. El Estado totalitario sería para el escritor comunista un signo de los tiempos, una suerte de imperativo histórico que prevalecería sobre cualquier forma de pluralidad social, política, cultural o económica, incompatible con las modernas formas de organización de la vida colectiva. "La centralización legal de toda la vida nacional en las manos del grupo dominante acaba siendo "totalitaria"”, afirma Gramsci en

4 Véase el artículo «Verso l'instaurazione del sistema totalitario: Liste fasciste, liste "bis", liste fiancheggiatrici, ecc», L'Unità, 20-2-1924. 
un pasaje de sus Cuadernos que sufrió una significativa modificación entre 1930 y 1934: mientras, en la primera versión, «la centralización» resultaba «frenética y absorbente», al reescribir el texto cuatro años después la calificó, como se ha visto, lisa y llanamente de «totalitaria» (Traverso, 2001: 275-278)5.

Los diarios de sesiones de la Cámara de Diputados muestran la creciente presencia del adjetivo totalitario/a en el lenguaje parlamentario desde su irrupción en 1923: de 4 ocurrencias en la XXVI legislatura (1921-1924), se pasará a 18, 71 y 77 en las siguientes, antes de experimentar una notable caída en la última legislatura fascista, inaugurada en 1939 (véase el gráfico 1). La casi completa fascistización del Parlamento a partir de 1929 hace que desde entonces su significado corresponda en exclusiva al que le atribuía el fascismo, con un sentido que fluctúa entre la banalidad y la redundancia, como cuando en abril de 1929 el secretario general del partido, Augusto Turati, dirigió al Parlamento el mayor cumplido que podía hacerle un fascista: «Questa Camera [è] totalitaria e fascista nello spirito e nella forma» (AAPP, 29-4-1929: 4). El mismo carácter redundante tiene la definición del nuevo Estado como «Stato forte, totalitario", y del régimen como "unitario e totalitario" (AAPP, 27-21931: 4003; AAPP, 3-5-1939: 76). Que un dirigente fascista instara en cierta ocasión a realizar un «studio organico totalitario» del problema del transporte indica el grado de trivialización al que estaba llegando el término como exponente de un lenguaje ya muy estereotipado (AAPP, 25-5-1934: 246).

No ocurrió lo mismo con la voz totalitarismo, ajena por lo general a la fraseología fascista y de la que hasta la caída del régimen solo se registran tres apariciones en los diarios de sesiones del Parlamento. En una de ellas, un diputado fascista rebate lo que considera una acusación infundada, pero muy extendida en medios católicos, contra el Estado mussoliniano: «Il vostro totalitarismo porta a la statolatria» (AAPP, 5-6-1929: 700). Era, efectivamente, el principal cargo que la oposición católica solía hacer al fascismo. Los otros dos usos de totalitarismo, en intervenciones de sendos diputados fascistas, serían puramente anecdóticos (AAPP, 16-3-1933: 8329; AAPP, 13-5-1937: 3759), y nada indica que en otros ámbitos del lenguaje oficial el término tuviera mayor fortuna. No figura, por ejemplo, entre las 1.079 voces que componen el $D i$ -

5 Marcello Montanari, en su edición de textos de F. Neuman, H. Arendt y A. Gramsci sobre el totalitarismo, titula el capítulo dedicado a este último "Antonio Gramsci: L'analisi dei totalitarismi nei Quaderni del carcere», pero lo cierto es que el concepto de totalitarismo como tal no aparece en los pasajes seleccionados — ni probablemente en la obra de Gramsci, salvo en forma de adjetivo- y que el epígrafe titulado por Montanari «Totalitarismi e società di massa» recoge las reflexiones de Gramsci sobre el cesarismo, que es algo bien distinto (Montari, 2004: 69-96). 
zionario di politica del Partito Nazionale Fascista, editado en 1940. Se diría que mientras el adjetivo totalitario/a, que sí aparece en el Dizionario, por ejemplo, en las voces "Regime» y «Stato», se incorporó plenamente a la terminología autorreferencial del fascismo, totalitarismo fue excluido y en cierta forma repudiado por el régimen, tal como sugiere un artículo aparecido en la prensa fascista en 1927 denunciando «il totalitarismo distruttore delle opposizioni» (artículo aparecido en La Tribuna y reproducido por La Stampa, 29-3-1927). El propio Mussolini lo utilizó con un sentido claramente peyorativo en uno de sus últimos discursos, ya en plena República Social Italiana: el «totalitarismo» encontraría «la sua eccelsa espressione nella Russia dei sovieti»; el modelo fascista italiano, por el contrario, se erigía en la única alternativa racional frente al «totalitarismo di Stato» y el «individualismo dell'economia liberale» ${ }^{6}$. No parece que la voz totalitarietà, de la que hay algún caso aislado en la retórica fascista ${ }^{7}$, llegara a cuajar como alternativa a un ismo que, a diferencia del adjetivo originario, podía identificarse con el lenguaje del adversario.

Y así era. El escaso rastro que totalitarismo dejó hasta 1945 corresponde por lo general a la oposición antifascista que actuaba en la clandestinidad o en el exilio. Solo así se entiende el contraste que se aprecia en la evolución del adjetivo totalitario/a y del sustantivo totalitarismo en el gráfico generado por Google Ngram Viewer al medir la presencia de uno y otro en las fuentes impresas escritas en italiano digitalizadas por esta base de datos (véase el gráfico 2). El hecho de que el fascismo represente la versión dominante del lenguaje político italiano entre 1922 y 1945 y el distinto trato que dispensó al adjetivo y al ismo explicarían el enorme desfase entre el abundante uso del primero y la casi inexistencia del segundo en el gráfico de Ngram hasta principios de los años cuarenta. La marginalidad de totalitarismo sería, pues, la consecuencia lógica de la propia marginalidad política de quienes lo utilizaban en textos críticos con el régimen, a menudo escritos en el exilio. Es el caso del artículo de Luigi Sturzo «El Estado totalitario», publicado en 1935 en la revista española Cruz y Raya. Tras afirmar que la expresión que da título a su ensayo es «un nombre de acuñación reciente, cuyo significado puede hacerse remontar a los imperios asirios y babilónicos», aunque hubiera sido «renovado y definido» por el fascismo (Sturzo, 1935: 7), Sturzo presenta «el totalitarismo bolchevique, o fascista, o nazi» como el modelo primigenio que siguen otros países europeos (Austria, Polonia, Portugal...) y enumera las «premisas lógicas del totalitarismo» en tanto

6 Discurso pronunciado por Mussolini en Milán el 16 de diciembre de 1944 (Discorso del Lirico, también conocido como Discorso della riscossa); Galli, 2008: 254.

7 La utiliza el propio Mussolini en una intervención parlamentaria en la que defiende «la totalitarietà del Regime» (AAPP, 8-12-1928: 9767). 
que «exaltación mística de un principio suprahumano: lo absoluto de la clase, de la nación o de la raza» (Sturzo, 1935: 10 y 38).

Pese a que el término se movía sobre todo en la órbita de la oposición no comunista, especialmente católica ${ }^{8}$, el PCI lo utilizó también en ocasiones esporádicas, pero significativas, como cuando en septiembre de 1937 L'Unità exhortó, al cumplirse "quindici anni di regime fascista ed undici di "totalitarismo"”, a luchar por el establecimiento en Italia de una República democrática. Al año siguiente, el órgano comunista Lo Stato Operaio se hacía eco del «malcontento del popolo contro il totalitarismo fascista» (1938: vol. 12-13: 386), y el secretario general del partido, Ruggero Grieco, en un largo artículo publicado en el aniversario de la muerte de Gramsci, instaba a sus correligionarios a observar con atención las movilizaciones populares por la libertad y la democracia, por modestas que fueran, y los esfuerzos del pueblo por romper la «cappa di piombo del totalitarismo" (L'Unità, 1938, Anno XV, n. 1). Un año después, L'Unità elogiaba la contribución del papa Pío XI, recientemente fallecido, a la lucha "contro la barbarie razzista e contro il soffocante totalitarismo fascista» (L'Unità, 1939, Anno XVI, n. 2). El propio periódico, en un artículo titulado «Guerra totalitaria», había denunciado la brutalidad del bando sublevado en la Guerra Civil española, un acontecimiento que, a tenor del título adoptado por L'Unità, podía verse - de momento- como el colofón inevitable del ciclo histórico de la «guerra total» desencadenada en 1914 (L'Unità, 1938, Anno XV, n. 1).

\section{LA GUERRA FRÍA: UN NUEVO PARADIGMA}

El final de la Segunda Guerra Mundial y el comienzo de la Guerra Fría inauguraron, también en Italia, la edad dorada del concepto de totalitarismo. Nacía así el llamado "paradigma totalitario» (Siegel, 1998), una interpretación del fenómeno tributaria mucho más del enfrentamiento Este/Oeste que de la experiencia histórica del periodo de entreguerras. Como ocurre en la mayoría de las lenguas occidentales, a partir de 1945 la utilización de totalitariola y totalitarismo experimentó en italiano un incremento extraordinario, reflejado

8 Véase, por ejemplo, la crítica a esa "folle e mostruosa interpretazione di "totalitarismo" - così lo chiamano- che si confonderebbe col panteismo dello Stato pagano", vertida en el artículo "La restaurazione cristiana e "l'unità della patria negli spiriti"”, publicado en el órgano de la Compañía de Jesús La Civiltà Cattolica, 1929, II: 202. También Alcide de Gaspari y su impugnación del «totalitarismo statale» —al igual que del «totalitarismo socialista»— en sus Scritti di politica internazionale; De Gaspari, 1933-1938: 498, 477 y passim, y Luigi Sturzo en sus obras del exilio. 
tanto en la base de datos Google Ngram Viewer como en los diarios de sesiones del Parlamento y en los archivos digitales de los periódicos La Stampa y L'Unità (véanse los gráficos 1, 2 y 3). Este último caso contrasta con la aversión del comunismo internacional, y en menor medida de otros sectores de la izquierda, hacia un concepto que se asociaba con la propaganda anticomunista y, consiguientemente, con el discurso político del enemigo.

La excepción italiana se entiende mejor si se recuerda que el término tuvo ya una cierta presencia en la prensa comunista de los años veinte y treinta, que la voz totalitarismo nació en los medios de la oposición a Mussolini y que, a diferencia del adjetivo, nunca perdió del todo su aura antifascista. De todas formas, para evitar equívocos, L'Unità tuvo que reformular el concepto de manera que encajara en su ideario y en su estrategia y pudiera distinguirse del sentido anticomunista que le daban sus adversarios. Una definición del Estado totalitario publicada por el periódico en junio de 1945 nos muestra el tipo de bricolaje semántico llevado a cabo por los comunistas italianos:

Stato totalitario significa esclusione dalla vita politica delle grandi masse lavoratrici, significa annullamento di ogni conquista politica, economica, sociale, significa impoverimento verticale dei lavoratori e verticale arricchimento di esigui gruppi finanziari (L'Unità, 24-6-1945).

El PCI, a diferencia de otros partidos hermanos, estaba dispuesto a hacer suya una noción ciertamente incómoda, pero a condición de darle la vuelta a su significado. Mientras en el lenguaje político dominante servía para recordar las concomitancias entre fascismo, nazismo y comunismo y advertir sobre el peligro de pasar, tras la caída de Mussolini, a una dictadura de signo contrario, la prensa comunista, que a menudo tuvo que rebatir «la solfa del nostro "totalitarismo"” (L'Unità, 19-1-1947), se sirvió del concepto como un arma arrojadiza contra la democracia cristiana. "Giannini prende posizione contro il totalitarismo D.C.», titula L'Unità en octubre de 1947 (L'Unità, 17-101947). En la mayoría de los casos, las críticas a los democristianos se formulaban mediante la locución «totalitarismo clerical», que los convertía en clericales y totalitarios al mismo tiempo. "Democrazia parlamentare o totalitarismo clericale?»: tal era la disyuntiva que se planteaba en Italia en vísperas de unas elecciones legislativas, según la portada del periódico del 29 de mayo de 1953. Cinco años después, a punto de celebrarse unos nuevos comicios, el PCI llamará de nuevo - leemos en un aparatoso titular de L'Unità — «a votare contro il totalitarismo clericale» (L'Unità, 19-3-1958). Hasta 62 veces, la primera en 1949 y la última en 1960, recurrió el periódico comunista a una expresión que debió de encontrar particularmente feliz. No era un hallazgo privativo de L'Unità, sino una pieza más del lenguaje comunista en la década de los cin- 
cuenta, tal como indica el título de un artículo publicado en 1949 por Pietro Ingrao en el semanario Rinascita: "Verso il totalitarismo clericale» (Ingrao, 1949). La acusación de totalitarismo que las fuerzas gobernantes solían lanzar contra los comunistas cobraba así un inesperado efecto bumerán. El secretario general del partido, Palmiro Togliatti, lo dirá claramente en una intervención parlamentaria: tras el anticomunismo de la democracia cristiana y su afán por alcanzar el poder absoluto latía un totalitarismo apenas enmascarado («un totalitarismo appena mascherato») (AAPP, 7-4-1960: 13569).

Cada cual tenía, pues, sus propios motivos para recurrir a un término que a partir de 1945 ocupó un espacio central en el discurso político italiano. De ahí el incremento exponencial de su uso tras el final de la Segunda Guerra Mundial, tal como ocurre en otros países y en otras lenguas occidentales. Que su apogeo se produzca entre mediados de los cuarenta y principios de los cincuenta se explica por la confluencia en su empleo de dos discursos políticos distintos, incluso contrapuestos: el discurso antifascista, que ajusta cuentas con el pasado inmediato, y el discurso anticomunista que corresponde a los primeros años de la Guerra Fría. El descenso en su uso a partir de comienzos de los años cincuenta respondería al protagonismo decreciente del pasado nazi-fascista en el debate político, mientras el conflicto comunismo-anticomunismo se mantenía estable hasta el comienzo de su declive con la distensión.

Estas tendencias, comunes a la evolución del concepto en el resto del mundo occidental, fueron especialmente acusadas en la Italia de la posguerra, sin duda por la importancia del debate histórico en torno al fascismo, por el enorme peso del PCI en la política nacional y por la existencia de un partido neofascista, el Movimiento Social Italiano, con representación parlamentaria y señalado unánimemente "come l'espressione vivente del totalitarismo», según la queja expresada por uno de sus diputados (AAPP, 13-7-1960: 15863). La suma de estos factores motivó una notable presencia de los términos totalitariola y totalitarismo en los diarios de sesiones del Parlamento como catalizadores del antagonismo extremo que enfrentaba, principalmente, al partido comunista y a la democracia cristiana, tal como se puso de manifiesto en una sesión de febrero de 1949 en la que un diputado democristiano gritó, dirigiéndose con toda probabilidad a los comunistas, «Abbasso il totalitarismo! Voi siete dei servi!». Este exabrupto provocó los aplausos de la derecha y las protestas de la izquierda del hemiciclo, de donde surgió el grito, un tanto extemporáneo, de «Viva la repubblica popolare ungherese!» (intervenciones de los diputados Cremaschi y Carlo, respectivamente; AAPP, 8-2-1949: 6151). La misma división de opiniones se produjo cuando el primer ministro, Mario Scelba — discípulo político de Luigi Sturzo—, definió la «democrazia politica» como "l'antitesi del totalitarismo che storicamente ha trovato la sua espressione nel fascismo, nel nazismo e nel comunismo» (AAPP, 18-2-1954: 5532). Los democristianos recurrieron también en ocasiones a reforzar el signi- 
ficado peyorativo del término añadiéndole uno o varios adjetivos ad hoc que se asociarían inevitablemente con el adversario. «Totalitarismo rosso», «totalitarismo materialista e marxista», "totalitarismo socialcomunista» $\mathrm{y}$ "totalitarismo operaio» serán algunas de las fórmulas empleadas a tal fin.

Era, pues, un concepto en disputa, más próximo al lenguaje del centroderecha, pero en absoluto circunscrito al mismo. El caso italiano se salía por tanto del patrón lingüístico de la Guerra Fría en el resto del bloque occidental, en el que, en palabras de Enzo Traverso, «la notion de totalitarisme se trouva [...] être le monopole quasi exclusif de la culture conservatrice et du libéralisme» (Traverso, 2001: 59). Solo conociendo la especificidad italiana se entiende la perplejidad que causó en un autor británico la publicación en 1951 del libro de Lelio Basso Due totalitarismi: Fascismo e democrazia cristiana, una recopilación de artículos y conferencias que empezaba en 1943, con la caída de Mussolini, y terminaba en 1951, con un texto titulado «L'Italia fra due totalitarismi», en el que Basso denunciaba la «involuzione totalitaria» que estaba viviendo el país (Basso, 1951: 258). En opinión del reseñista de International Affairs, el título elegido por este socialista de izquierdas entrañaba un peligroso oxímoron:

In normal English or Italian usage the word "totalitarian» is used to describe party dictatorships of the Nazi-Fascist or Stalinist type. Signor Basso uses words in their quite opposite, Stalinist-Marxist, sense. He is a typical exponent of this latter outlook and he makes all the usual accusations against the Western countries (Wall, 1952: 106).

Puede que «in normal English» el concepto tuviera ese significado, pero no necesariamente en «Italian usage». Ahí radicaba precisamente la excepción italiana, al menos durante la llamada Primera Guerra Fría (1945-1962).

El comienzo de la distensión en 1962, tras la crisis de los misiles en Cuba, traerá consigo una mejora de las relaciones Este/Oeste que habría de reflejarse en un lenguaje menos beligerante y en el consiguiente declive de la voz totalitarismo, en lo que solo puede interpretarse como el pago de un peaje conceptual a la distensión. No es que Italia permaneciera al margen de ese cambio de tendencia, pero la evolución del término en el discurso político italiano a partir de principios de los sesenta no estará exenta, como hasta entonces, de una cierta singularidad.

\section{DISTENSIÓN (MA NON TROPPO)}

En los años sesenta y setenta, el término totalitarismo siguió principalmente en la órbita democristiana en el marco de una propaganda anticomu- 
nista animada, entre otras cosas, por el miedo al llamado sorpasso, es decir, a un resultado electoral que situara al partido comunista por delante de la democracia cristiana. Los dirigentes democristianos acusaban al PCI de querer instalar un «régimen totalitario» una vez alcanzado el poder y en su propaganda insistían en la equiparación entre fascismo y comunismo como formas de totalitarismo. En este contexto, la DC se presentaba como baluarte contra cualquier forma de totalitarismo. En palabras del que fue cinco veces presidente del Gobierno, Amintore Fanfani, la DC era «el partido de la libertad del hombre y de la libertad del sistema social [...], contrario al totalitarismo fascista, pero también al totalitarismo colectivista» (La Stampa, 19-7-1974).

Además, durante estos años se registra un aumento de referencias al supuesto totalitarismo del PCI por parte del partido socialista italiano (PSI), con el objetivo de ganar votos a la izquierda, aproximándose a la socialdemocracia europea y desmarcándose de la tradición leninista. La polémica entre comunistas y socialistas, sobre todo en los setenta, se convertirá en algo habitual. Especial relevancia tuvo el artículo del secretario del PSI, Bettino Craxi, titulado «Il Vangelo socialista», publicado en 1978. Craxi afirmaba que "el comunismo es orgánicamente totalitario» y que se rige por un "totalitarismo del consenso» cuya implantación era precedida por un «totalitarismo de la coerción». El líder socialista atacaba al comunismo leninista, definiéndolo como «una religión travestida de ciencia». Esta es la razón por la que «no quiere tolerar rivales y es, en una palabra, "totalitario"” (L’Espresso, 27-8-1978). En la misma línea, uno de los intelectuales del partido, el filósofo Luciano Pellicani, afirmaba que el PCI era «orgánicamente totalitario».

Desde otra fuerza política de inspiración socialista, Giuseppe Saragat, quinto presidente de la República italiana y secretario del Partido Socialista Democrático Italiano, recordaba a los comunistas el duro juicio del escritor marxista György Lukács («con el estalinismo el mundo socialista ha perdido cincuenta años») como demostración de la incapacidad del sistema político comunista «de liberarse de los esquemas del totalitarismo». De ahí que se preguntara "icómo pueden los comunistas pedir votos en nombre de aquellos errores que el PCI nunca ha reconocido?» («Come possono i comunisti chiedere voti in nome di questi errori che il pci non ha sconfessato?», La Stampa, 21-11-1964).

Debido a este clima, los representantes del partido se esforzaban por evitar que la propaganda anticomunista occidental y los políticos opositores vinculasen el concepto de totalitarismo con el comunismo, estigmatizando sus esfuerzos democráticos y cuestionando su independencia de la URSS. L'Unità seguía recurriendo al término de la manera más acorde a su ideario y estrategia, acusando a los otros partidos, de la DC al PSI, de apelar a la comparación del PCI con el totalitarismo soviético en el marco del «chantaje del miedo» 
(«ricatto della paura»). El periódico comunista criticaba además el recurso al «espectro del totalitarismo marxista» ("lo spettro del totalitarismo marxista»), tachaba la acusación de totalitarismo de "manido caballo de batalla» («logoro cavallo di battaglia») y censuraba la tendencia a reducir el leninismo "a un puro y compacto totalitarismo de estilo asiático» («leninismo viene ridotto a puro e compatto totalitarismo di stampo asiático») (L'Unità, 25-3-1977, 12-5-1979 y 4-7-1979).

Aunque en menor número que en el pasado, el periódico del PCI siguió asociando el término a la Democracia Cristiana, por ejemplo al hacerse eco de las críticas de Saragat al integrismo clerical como «una forma atenuada de totalitarismo", según la información publicada de forma destacada tanto en la edición del día 5 como en la del día 7 de abril de 1974. Como Saragat, el PCI se mostraba crítico ante la posibilidad de «un monopolio del poder de una Democracia Cristiana orientada en sentido antipopular, galvanizando las fuerzas más reaccionarias y clericales del mundo católico y de la misma jerarquía eclesiástica» (Tatò, 1985: 40). Asimismo, el secretario del PCI (19721984), Enrico Berlinguer, polemizó duramente con el diputado democristiano Flaminio Piccoli sobre su propuesta de reforma del sistema electoral, que concedía tal prima al partido ganador que podría contar con mayoría absoluta en el Parlamento sin necesidad de obtener una clara mayoría en sufragios. Berlinguer consideraba la propuesta tan antidemocrática como lo fue en la época fascista la ley Acerbo de $1924^{\circ}$. En su opinión, era una ley perjudicial para el pluralismo, que impediría al Parlamento seguir siendo «el reflejo del país» y afectaría gravemente a la dialéctica democrática (L'Unità, 22-4-1979). Berlinguer compartía la misma idea de Togliatti de que la DC, tras su afán de alcanzar el poder absoluto, escondía en realidad una tendencia encubierta al totalitarismo.

En la misma línea crítica, L'Unità publicó las palabras de Dom Giovanni Franzoni, famoso abad benedictino que se distinguió por una militancia activa en el PCI y por ser expulsado de la Iglesia, amonestando a los obispos que, en su opinión, agitaban «el fantasma del comunismo como totalitarismo y amenaza para la libertad de culto", mientras con los partidos de derechas se mostraban benevolentes y serviles (L'Unità, 17-6-1976). Dentro del Parlamento, el Partido Comunista aplaudía intervenciones como las de Tullio Vecchietti, secretario del Partido Socialista de Unidad Proletaria (PSIUP), que finalmente entró en el PCI en 1972. En una sesión parlamentaria sobre la guerra de Vietnam, Vecchietti afirmó que el imperialismo norteamericano

9 Para muchos fue el principio del totalitarismo de Mussolini, que se aseguraba así el poder alcanzado tras la Marcha sobre Roma. 
estaba cosechando en Vietnam una derrota de la «inmensa maquinaria de guerra americana» a la hora de imponer una civilización "que en su carácter autoritario y totalitario encuentra tanto su fuerza exterior como su interna e íntima debilidad» ${ }^{10}$.

En su intento de contrarrestar la propaganda anticomunista, los políticos del PCI rechazaban poner a la misma altura el totalitarismo fascista y el totalitarismo comunista, criticando a aquellos que querían establecer una implícita analogía entre fascismo -o nazismo- y comunismo. El PCI recordaba su papel en la resistencia, cuando se enfrentó al fascismo en la lucha partisana: «El fascismo fue estatalismo, autoritarismo, totalitarismo: en antítesis a ello, la democracia debía consistir en el desplazamiento del poder del vértice a la base» (intervención del diputado comunista Giuseppe Fasoli, AAPP, 6-51970: 17198). L'Unità criticó una y otra vez la equiparación que la DC y las otras fuerzas políticas italianas pretendían hacer entre comunismo y fascismo. El órgano del PCI mostraba especial irritación cuando estas acusaciones eran lanzadas por representantes de la Democracia Cristiana, como Giovanni Spadolini, Andreotti o Fanfani, en el marco del debate parlamentario o en actos organizados por el mismo partido. Víctima frecuente de las críticas comunistas, Giulio Andreotti recibió un ataque particularmente duro en un editorial del diario titulado «Sostanza reazionaria». En él se calificaba de «infamia» y de "escandalosa» aquella parte de un reciente discurso del líder democristiano en la que, "bajo la etiqueta de "totalitarismo"”, se equiparaba a los comunistas y a los fascistas (L'Unità, 5-7-1972). El partido mostró asimismo su enfado cuando, tras la Revolución de los Claveles en Portugal, Fanfani tachó al PCI de totalitario, dificultando así posibles acuerdos políticos entre los dos partidos. Por esa razón, en la misma sesión parlamentaria donde se debatió el tema, Berlinguer reafirmó en diferentes ocasiones su convencimiento de que «socialismo y democracia son inseparables»" ${ }^{11}$. Para Berlinguer, la equiparación que la DC hacía entre comunismo y fascismo como regímenes totalitarios era especialmente inapropiada en un momento - los llamados «años de plomo»— en que el PCI proponía una línea unitaria para enfrentarse a la grave crisis que afligía al país.

A medida que la acusación se convirtió en un tema importante en la campaña de desprestigio democristiano, el PCI fue endureciendo su postura.

10 "Che nel suo carattere autoritario e totalitario ha la sua forza esteriore, ma anche la sua interna, intima debolezza» (AAPP, 18-7-1968: 444).

11 Tras la Revolución de los Claveles y la idea de Cunhal de "prohibir» la DC portuguesa, «i comunisti sono tornati a essere per la Democrazia Cristiana il partito totalitario e schiavo di Mosca, il nemico numero uno dei regimi democratici» (Valentini, 2014). 
Así, en el marco del XV Congreso celebrado en Roma, del 30 de marzo al 3 de abril de 1979, Berlinguer se mostró intransigente respecto a la opinión de aquellos que consideraban que la Segunda Guerra Mundial, con sus catástrofes y sus despiadadas tragedias, había sido provocada por «opuestos totalitarismos de Estado o por "regímenes totalitarios de distinta naturaleza"». El líder comunista tachaba de "profundo error de juicio cualquier forma de aproximación del régimen soviético a los regímenes fascistas» (Berlinguer, 1979: 16). Lamentaba además que parte de la DC rechazase la confrontación y el diálogo "con el método del prejuicio ideológico y de las habituales calumnias gratuitas acerca de un supuesto totalitarismo de los comunistas» (L'Unità, 17-2-1975).

Estos ejemplos muestran hasta qué punto, lejos de la distensión que presidía las relaciones internacionales, el clima entre los dos principales partidos italianos seguía marcado por un antagonismo que ni siquiera se redujo con el nuevo proyecto político del PCI: el eurocomunismo. Fue una iniciativa promovida por su secretario general, Enrico Berlinguer, que lo definió como «una colaboración no episódica entre los partidos comunistas del occidente capitalista y una relación unitaria con las demás fuerzas de la izquierda obrera y democrática interesadas en la lucha por la transformación socialista de la sociedad» (Berlinguer, 1977a: 359). En política nacional, los eurocomunistas buscaban la construcción de alianzas llamadas concentración, compromiso histórico o reconciliación nacional, encaminadas a alcanzar una mayoría suficiente que permitiese adoptar las medidas necesarias para «avanzar hacia el socialismo por una vía democrática, que es una vía de lucha de clases y de lucha de masas» (Berlinguer, 1977b: 44). El compromiso histórico, plasmado en el XIII Congreso del PCI de 1972 — aunque sus orígenes venían de tiempo atrás-, auspiciaba una colaboración orgánica entre los partidos de mayor representación nacional, intentando conseguir el máximo consenso posible en torno a las instituciones democráticas. La grave crisis político-económica que sufría el país llevó al Partido Comunista a proponer una «tregua política», mostrándose dispuesto a formar una coalición con los diferentes partidos democráticos para solucionar los problemas más graves y urgentes de Italia. El eurocomunismo sería inseparable además de una postura más crítica con la Unión Soviética.

Este cambio de actitud no dio, sin embargo, los resultados esperados. La DC no dejó de criticar el supuesto totalitarismo del PCI y mostró en repetidas ocasiones su desconfianza respecto a la propuesta eurocomunista. Incluso algunos representantes de la DC argumentaban que al totalitarismo fascista se había llegado invocando la presunta unidad de los italianos ${ }^{12}$, palabras que el PCI interpretó como parte de una estrategia de desprestigio del compromiso

12 Entrevista de Arnaldo Forlani al semanario Gente; L'Unità, 26-4-1975. 
histórico. Augusto Del Noce, filósofo y político de la DC, sostenía que el eurocomunismo era, en realidad, la sustitución de un modelo totalitario por otro "más eficiente y más completo", en apariencia menos violento y solo dialécticamente más predispuesto al consenso (Del Noce, 1978: 63).

La DC no era la única fuerza política nacional que desconfiaba del PCI. El mismo día en el que Berlinguer exhortaba a los parlamentarios italianos a un mayor entendimiento, argumentando que el país necesitaba «solidaridad, colaboración y concordia» y que "ya no sería posible crear una mayoría o un Gobierno dejando al Partido Comunista en la oposición», el socialdemócrata Pier Luigi Romita renovaba su escepticismo sobre las buenas intenciones del PCI, pese a la nueva actitud del partido, al advertir del peligro de entrar en una fase nueva "de unidades indiferenciadas y de totalitarismos enmascarados»" ${ }^{13}$.

Las distancias respecto a los otros partidos eran evidentes, pero también la necesidad y la posibilidad de superarlas, tal como el propio Berlinguer puso de manifiesto en un discurso parlamentario al referirse al Programa Común firmado por la izquierda francesa en junio de 1972. Este «acontecimiento histórico», como lo llamó Berlinguer, demostraba que fuerzas políticas diferentes podían alcanzar un acuerdo político sin renunciar a su propia personalidad, a su historia y a su ideología. En un tono de reproche a la clase política italiana, Berlinguer lamentó que los mismos que les acusaban de "totalitarismo e integrismo» fueran incapaces de entender que a veces la libertad consiste en dejar a un lado las diferencias ideológicas y alcanzar formas de convergencia que permitan buscar soluciones concretas y abrir nuevas perspectivas políticas (AAPP, 5-7-1972: 254).

Las fuerzas políticas italianas criticaban tanto la actitud del PCI respecto a la Unión Soviética como la ambigüedad dialéctica e indefinición teórica de la propuesta eurocomunista. No podían evitar preguntarse además si el renovado concepto de «hegemonía» no era más que «una variante "culturalizada" del totalitarismo» (Spadafora, 1978: 19). El PCI mostró especial irritación cuando los diputados democristianos elogiaron al partido afirmando que se había "portado bien» —es el caso de Colombo y Piccoli—, pero matizando que aún le faltaba dar «respuestas claras» sobre su alineamiento con Occidente y sobre cuál era su opción ante la cuestión de la hegemonía y el totalitarismo (L'Unità, 11-4-1978), un planteamiento que los comunistas consideraban especialmente ofensivo viniendo de un partido como la DC, sumido en una grave crisis moral.

A partir de los años sesenta y sobre todo en los setenta, el creciente protagonismo de la televisión cambiará las campañas electorales y por tanto el propio discurso político. Comprendiendo desde el principio el potencial del

13 «Non crediamo, tuttavia, che dalla fase delle preclusioni si debba passare alla fase delle unità indistinte e dei totalitarismi mascherati» (AAPP, 14-7-1977: 9135). 
medio televisivo, el PCI se mostrará muy interesado en el papel de la televisión tanto desde el punto de vista jurídico (su regulación) como práctico (su propia presencia en la "pequeña pantalla»). En su órgano oficial, se publicaron varios artículos —el primero el 29 de octubre de 1977, «La vicenda del "Corriere”»apelando a la necesidad de defender el "pluralismo informativo y de los medios de comunicación». Al mismo tiempo criticará las ayudas estatales y las injerencias gubernativas, la "omnipresencia» democristiana y la intromisión socialista. En 1982, en una intervención ante el Comité Central del partido, Berlinguer lamentará estar asistiendo a "una competición electoral de las más ásperas", caracterizada por una lucha indiscriminada "por la posesión de los medios de información y comunicación de masas, que está revelando la tendencia a reducir la democracia a formas de tipo totalitario» (L'Unità, 15-4-1982).

El incremento en la utilización de totalitariola y totalitarismo en 19631968 y 1979-1983 (gráficos 1, 2 y 3) coincide con importantes acontecimientos en el bloque comunista, como la Primavera de Praga (1968), la invasión soviética de Afganistán (1979) y la creación del Gobierno del general Jaruzelski en Polonia (1980), episodios que provocaron una profunda crisis dentro del Partido Comunista italiano y el consiguiente deterioro de sus relaciones con el PCUS ${ }^{14}$. Tampoco la situación interna en Italia era la más favorable. Los «años de plomo» estuvieron marcados por la llamada «estrategia de la tensión» (solo en 1977 se estima que hubo 2.128 atentados), cuyo punto álgido fue el asesinato del político democristiano Aldo Moro. En este contexto se produjo un aumento en las acusaciones de totalitarismo contra el PCI y la llamada izquierda extraparlamentaria (Brigate Rosse, Lotta Continua, Potere Operaio...). También se registra un cambio por parte del periódico comunista en el uso del término totalitarismo. A finales de los años setenta y en los ochenta se observa, más que un intento de encajarlo en su ideario, la ampliación de su uso a otros ámbitos y otros contextos. Se critica el «totalitarismo industriale» que perjudicaba a las antiguas civilizaciones agrícolas (L'Unità, 25-10-1977); el «totalitarismo delle leggi di mercato» (L'Unità, 23-5-1979); el «moderno totalitarismo occidentale», identificado con el conformismo de masas (L'Unità, 22-11-1979); el «totalitarismo económico», promovido por los países capitalistas (L'Unità, 14-4-1986) y, finalmente, el «totalitarismo dei consumi» (L'Unità, 10-12-1988). En un artículo sobre el libro de Orwell 1984, el diario hacía suya la idea de Umberto Eco publicada en el preámbulo

14 Tras el golpe de Polonia, Berlinguer consideraba agotada la «spinta propulsiva della Rivoluzione socialista di ottobre» (G. Mammarella, "Il partito comunista italiano», en Pasquino, 1995: 303). El malestar y la dificultad del partido en este periodo son descritos magistralmente en las memorias de Luciano Barca (2005), especialmente, en el vol. II. 
de la reedición de Mondadori: Orwell no denunciaba solo al régimen soviético, sino, de forma más amplia y general, «el totalitarismo como emblema del mundo moderno». La realidad totalitaria presentada por Orwell era la de «la civilización de masas y su sistema de lenguaje y de comunicación» (L'Unità, 31-3-1984). A tal fin, resulta interesante destacar que en un "speciale-libri» comentando nuevas publicaciones sociológicas, se hacía hincapié en «la ambigüedad del concepto de totalitarismo" y se ponía como ejemplo «el uso que los intelectuales americanos hicieron [de él] en el periodo de la guerra fría» (L'Unità, 14-9-1977).

Finalmente, en la etapa eurocomunista, el PCI, lejos de normalizar su relación con el concepto, empezó a mostrarse dubitativo a la hora de utilizarlo. En cualquier caso, se evitaba su uso para referirse a la situación soviética, pese al contexto internacional. Frente a la creciente ambigüedad lingüística del PCI, hay que destacar dos excepciones. Por un lado, Vittorio Strada, eslavista y miembro del partido, que en una intervención en el Centro di Studi e di Documentazione sui Paesi Socialisti dell'Istituto Gramsci (1978) reconoció en el sistema soviético elementos propios de un sistema totalitario: «El totalitarismo se basa en un sistema monopartidista, sobre una ideología que se propone como ideal una sociedad homogeneizada y simplificada, basada en una movilización y manipulación permanente de las masas y en el control centralizado y capilar de los medios de formación e información» (V. Strada, «Politica e cultura nell'URSS», en Bertolissi, 1978: 163-164). Se trató de una posición aislada en el panorama intelectual de la izquierda y su valoración de la situación rusa no tuvo excesiva resonancia. El propio Strada abandonó el partido a principios de los años ochenta. La segunda excepción la encarna Umberto Terracini, histórico dirigente del PCI, que en una célebre y extensa entrevista se mostró especialmente crítico con la situación política en la URSS. Además de denunciar el «totalitarismo integral del Estado soviético, cuyas asambleas representativas $[\ldots]$ constituyen un aparente poder decisorio», censuró «la eterna aprobación unánime de cualquier propuesta presentada por los órganos del vértice del partido y del Estado» (La Repubblica, 24-2-1976).

Pese a los avances electorales de la época eurocomunista, el PCI no logró hacer realidad su ambición de llegar al gobierno. La estrategia del compromiso histórico generaba más dudas que respuestas sobre cuál era el camino para alcanzar el poder. Algunos dirigentes del PCI recordaron las palabras de Giorgio Amendola de que un partido que no alcanza sus objetivos en cincuenta años - y tres generaciones de militantes - está obligado a buscar las razones de este fracaso y a transformarse (Rinascita, 28-11-1964). Ante esta situación, el PCI se preguntaba qué tipo de estrategia debía seguir, si volver a la corriente prosoviética o profundizar en el cambio con el riesgo de incurrir en posiciones socialdemócratas. 


\section{IV. ÉRASE UNA VEZ EL GRAN PARTIDO COMUNISTA}

El antagonismo existente entre el partido comunista y los demás partidos (DC, PSI, Movimiento Social Italiano y, sobre todo, Partido Radical) se agudizó en los años ochenta y principios de los noventa. En este contexto, el término totalitarismo mantuvo su sentido abiertamente polémico, como un concepto en disputa entre las principales fuerzas en presencia. La oposición no comunista utilizaba a su favor las dudas que generaba la posibilidad de un comunismo respetuoso con la democracia y sin tentaciones totalitarias. A tal fin, estableció una especie de escala capaz de medir su credibilidad democrática: poco o nada creíble, bastante creíble, totalmente de buena fe. Esta actitud provocó un profundo malestar en el PCI, que respondió airado ante el «test de democracia» exigido por las demás fuerzas políticas, poco o nada exigentes en cambio con ellas mismas.

Como en años anteriores, la estrategia comunista perseguía un entendimiento con las restantes fuerzas de izquierda. Giorgio Napolitano, histórico militante comunista y futuro presidente de la República, no podía entender por qué desde la izquierda se seguía acusando al PCI de totalitarismo (L'Unità, 14-9-1983). Más contundente fue el artículo de Alfredo Reichlin "Questa Dynasty all'italiana», en el que, comentando la situación nacional, acusaba a las demás fuerzas políticas de la merma que estaban sufriendo la democracia, el pluralismo político, ideológico y cultural y la libertad de información. El autor se preguntaba por qué «tenemos que soportar que nos hagan exámenes sobre democracia, como si la elección concreta, actual, fuese entre liberalismo y totalitarismo, Este-Oeste, o mercado sí o no, más Estado o menos Estado». Reichlin concluía diciendo que era "el "capitalismo real" el que está entrando en conflicto objetivo con la democracia» (L'Unità, 9-11-1986).

El PCI siguió utilizando el término en otros contextos y para otros fines, como cuando en 1986 el diputado Luciano Violante relacionó el «totalitarismo» con la mafia, a la que acusó de hacer política y de dirigir «sectores de partidos e instituciones». Para el diputado comunista, el totalitarismo de la mafia era evidente en su estructura y en su gestión del poder. Recordando los asesinatos de los periodistas Siani y Fava, el que fuera presidente de la Comisión Parlamentaria Antimafia (1992-1994) consideraba que la violencia, la intolerancia y el deseo de silenciar a quienes la denunciaban constituían «signos de la concepción totalitaria de la política, [...] un elemento de dominio, de totalitarismo, de destrucción de la libertad» (AAPP, 11-3-1986: 39871-39877). Unos años antes, Violante recordaba la importancia de la «cuestión moral» y de la «autonomía política» respecto a las decisiones judiciales y el peligro de politizar la Magistratura, dándole responsabilidades políticas, tal como, en su opinión, estaba haciendo la DC: ahí era donde realmente se introducían «elementos de totalitarismo en el sistema» (AAPP, 14-11-1984: 20043). Ya en los 
ochenta, L'Unità criticará el totalitarismo de algunos países americanos como Nicaragua, Guatemala, Uruguay o Haití, sin dejar de señalar que los ingredientes totalitarios de tales regímenes eran «exportados» por los gobiernos de Estados Unidos y resultaban inseparables de su política imperialista. En esta línea, el diario comunista publicó varias entrevistas a Noam Chomsky en las que el lingüista norteamericano criticaba la política exterior de su país. En una de las más conocidas, L'Unità destacaba su idea de que el poder liberal en América era «tan totalitario como el leninista en la Unión Soviética» (6-5-1988).

Sin embargo, la situación del PCI cambió tras la imprevista muerte de Berlinguer, con la que empezó una etapa de desconcierto. Le sucedió como secretario general Alessandro Natta (1984-1988), histórico dirigente del partido, favorable a una política de aproximación a la URSS ${ }^{15}$, y que en realidad actuó como Caronte entre la vieja guardia y las nuevas generaciones, encabezadas por Achille Occhetto y Massimo D’Alema, que tomaron el control del partido en 1988 y que serán los artífices del final del PCI y del nacimiento del Partido Democrático de la Izquierda (PDS).

Fueron años turbulentos. La militancia estaba desorientada por los acontecimientos de 1989 y el partido mantenía una actitud ambivalente: por un lado, aspiraba a demostrar que el PCI no iba a derrumbarse por la caída del Muro de Berlín y que su vitalidad y fortaleza estaban fuera de discusión, y, por otro, intentaba marcar distancias con la experiencia soviética, de cuyo fracaso habría sido plenamente consciente. Esto explica el incremento extraordinario del uso de totalitarismo a partir de 1989, en particular en los años 1991 y 1994, coincidiendo con la decisión del PCI de cambiar de nombre. Se puede afirmar, parafraseando a Valdo Zilli, que en estos años el PCI pasó de "una conoscenza mitica» a una "conoscenza critica» de la Unión Soviética (Bertolissi, 1978: 168), que se tradujo en un deseo de alejarse de su sombra.

Caído el Muro de Berlín, L’Unità y los políticos comunistas empezaron a utilizar nuevamente sin recelos la palabra totalitarismo, pero esta vez de forma crítica, no solo para augurar el cambio en los países del socialismo real, sino también para reprochar la anterior experiencia totalitaria. Destacaban los artículos de apoyo a aquellos países del Este de Europa que emprendían su camino hacia el cambio: Polonia («Adiós, totalitarismo»); Hungría («en la Hungría liberada del totalitarismo florecen las cien flores de la democracia») o Rumania (animando al país a seguir adelante en el «intento de renunciar a los

15 Ante la caída del Muro, Natta afirmó desconsolado: «Aquí se derrumba un mundo, cambia la historia: ha ganado Hitler. Se realiza su designio medio siglo más tarde»; $L a$ Stampa, 8-11-2009. 
esquemas obsoletos del totalitarismo estaliniano impuesto a los comunistas rumanos y a su pueblo por el secretario general Nicolae Ceaucescu y su clan») (L'Unità, 18-8-1989, 23-10-1989 y 16-11-1989). No obstante, no se trató de una actitud unívoca, por lo que seguirán apareciendo artículos en defensa de la experiencia soviética y justificando sus errores.

En 1990, el órgano de PCI publicó un artículo de tímida autocrítica, "Eccesso di utopismo e idealismo le malattie dell'ultimo PCI», en el que, por un lado, se acusaba al partido de no haber sabido enfrentarse «a las deformaciones de su propia historia, así como a los acontecimientos que han llevado el Este europeo a la liberación total del totalitarismo comunista», y, por otro, se advertía del peligro de una situación que podía tornarse peligrosa y provocar «divisiones y rupturas internas irreversibles» (L'Unità, 24-10-1990). Fue una observación premonitoria. En el partido empezó una lucha fratricida entre aquellos que seguían defendiendo a la URSS y aquellos que consideraban su experiencia un fracaso y se mostraban dispuestos a criticar abiertamente el totalitarismo soviético. Entre estos últimos figura Cesare Luporini, que, al analizar el cambio registrado en la URSS y en el Este de Europa, señaló su carácter liberador por representar «el hundimiento del totalitarismo en su versión más orgánica: la "comunista" (L'Unità, 20-11-1989). En el sector crítico, destacó sobre todo Achille Occhetto, secretario general del PCI (1988-1991) y promotor de la llamada svolta della Bolognina. Si bien es cierto que, al igual que otros dirigentes comunistas, seguía mostrándose preocupado por la situación de los antiguos países comunistas ${ }^{16}$, Occhetto renegaba ya públicamente de la experiencia soviética y reprochaba a su partido haber tardado demasiado tiempo en llamar a las cosas por su nombre (L'Unità, 8-2-1990).

La escisión comunista fue un duro golpe, que dejó aturdida a la militancia y preocupados a los dirigentes. El futuro del PCI —el «iahora qué?»— se debatió en Rímini. Para algunos, como el filósofo y diputado del PCI Biagio de Giovanni, había que interpretar 1989 como un principio y un final: «El agotamiento del proyecto histórico del comunismo, la caída de un totalitarismo sin salida, [y] el inicio de un proceso democrático en el Este de Europa» (L'Unità, 2-2-1991). Para Occhetto, la izquierda tenía que volver a empezar desde Gorbachov («ripartire da Gorbaciov»): «No es un derrotado; ha ganado el verdadero desafío, el de liberar a la URSS del totalitarismo» (L'Unità, 3112-1991). El partido, en opinión de Occhetto, debía hacer un esfuerzo por

16 Invitaba a mantener los ojos abiertos «porque en algunos de estos países, existe el peligro de que se pase del viejo totalitarismo a unos procesos sociales y políticos de éxito imprevisible» (L'Unità, 22-9-1991). 
comprender las razones que provocaron la "crisis del totalitarismo comunista» (L'Unità, 7-1-1992).

Disuelto el PCI y sustituido por el PDS (febrero de 1991), el término totalitarismo mantuvo su presencia en L'Unità, que en su portada, debajo de la cabecera, había sustituido "Órgano del partido comunista italiano" por «Diario fundado por Antonio Gramsci». En un célebre artículo sobre Polonia y la derogación de la ley de aborto, el periódico preguntó irónicamente al Papa Wojtyla si quería sustituir el "totalitarismo materialista» por «el totalitarismo católico» (L'Unità, 5-5-1992), y, en pleno escándalo de Mani Pulite, Giovanni Dolino, del partido Refundación Comunista, criticó la situación italiana, la degradación de la democracia y el descrédito de la política y lanzó una inquietante advertencia: que «la ineficiencia y la corrupción movían el péndulo de la historia hacia nuevas formas de totalitarismo» (AAPP, 17-2-1993: 10138).

La Bolognina marcó el final del Partido Comunista Italiano. Occhetto intentó crear un nuevo partido que fuera algo más que una respuesta desesperada ante el ocaso de una ilusión ${ }^{17}$. Pero su apuesta renovadora no bastó para revitalizar a la izquierda italiana, dividida entre nostálgicos y socialdemócratas. En una entrevista en El País, el último secretario del PCI confesaba en 2009 que «había que poner a salvo nuestro empuje reformista, sacándolo de los escombros del totalitarismo para llevarlo al terreno de la libertad y de la democracia» ${ }^{18}$. Que finalmente no fuera así explica el final del mayor y más fuerte de los partidos comunistas occidentales.

\section{CONCLUSIONES}

El concepto de totalitarismo protagonizó en Italia, su patria natal, una historia singular que duró al menos tres cuartos de siglo. No es que se apartara por completo del "paradigma totalitario» del siglo $\mathrm{xx}$, es decir, del significado y de los usos dominantes en el resto del mundo occidental, pero en cada una de las grandes etapas que recorre desde su aparición en los años veinte, totalitarismo presenta rasgos específicos que permiten diferenciarlo de su trayectoria general en el discurso político contemporáneo.

17 El secretario del PCI mantenía la ilusión de que fuera posible «un cambio en la continuidad», una visión del socialismo como «movimiento permanente de reforma» (Occhetto, 2013: 262-266).

18 "Érase una vez el PCI», El Pais, 22-11-2009 (hemos corregido la traducción, muy deficiente, de estas palabras pronunciadas en italiano). 
Sorprende que un término acuñado en 1923 para denunciar y combatir al fascismo se integrara en tan poco tiempo en el lenguaje autorreferencial del nuevo régimen. Por el contrario, frente al doble uso del adjetivo totalitario - pro y antifascista, a gusto del consumidor-, la voz totalitarismo permanecerá por lo general anclada en el lenguaje antifascista y será ignorada o repudiada por el fascismo. Un estudio detallado de la aparición del concepto en Italia confirma, matiza o desmiente, según los casos, un relato historiográfico sólidamente establecido. Era sabido que el adjetivo fue acuñado por el liberal Giovanni Amendola en 1923 y asumido por Mussolini dos años después, cuando reivindicó ante el IV Congreso del Partido Nacional Fascista «la nostra feroce volontà totalitaria». En cambio, la atribución de totalitarismo al socialista Lelio Basso resulta desmentida por la existencia de un uso anterior en varios meses al artículo de Basso, fechado en enero de 1925, en el que, según los principales especialistas, apareció por primera vez el nuevo ismo político. En agosto de 1924, un autor anónimo vinculado al Partido Popular había señalado ya el «mayor grado de totalitarismo» que comportaba el régimen de Mussolini comparado con el despotismo tradicional (La Stampa, 31-8-1924). Una búsqueda más profunda y detenida de las raíces históricas del término muestra asimismo su relación con el cambio en el sistema electoral introducido por el fascismo. Ni mayoritario ni minoritario; el nuevo sistema era simplemente "totalitario»: toda la representación — no solo una parte, ni siquiera mayoritaria — correspondería a la fuerza ganadora (no hace falta decir cuál). Medio siglo después, Berlinguer recordaba la ley Acerbo de 1924 como antecedente de una reforma electoral en curso que apuntaba en la misma dirección: una suerte de totalitarismo encubierto, perpetrado por la coalición gobernante y en particular por la Democracia Cristiana, tras la fachada de una simple reforma electoral. Es curioso observar cómo algunos rasgos específicos del concepto en la Italia contemporánea — su dimensión electoral, por ejemplo- permanecen inalterables en contextos históricos radicalmente distintos.

El año 1945 marcó el comienzo de su edad de oro como ismo fundamental del discurso político del siglo xx. Se da, pues, la paradoja de que mientras la plenitud de los totalitarismos se produjo en el periodo de entreguerras, el esplendor del concepto se registró en la llamada Primera Guerra Fría (19451962). En esto, Italia no fue una excepción. Todos los indicadores muestran un aumento considerable del uso del término a caballo entre los años cuarenta y cincuenta, un claro declive a partir de entonces, tal vez con la excepción del lenguaje parlamentario, y una polarización ideológica en su uso y significado relacionada con el impacto de la Guerra Fría en la política interior del país. La especificidad italiana se aprecia en la transversalidad ideológica del término, usado no solo como arma arrojadiza contra el comunismo, sino por 
los propios comunistas, que lo emplearon a su vez contra sus adversarios de la derecha. Incluso en plena distensión y en un momento de reformulación general del discurso comunista, Enrico Berlinguer denunciará la tendencia natural de la Democracia Cristiana a monopolizar el poder con sutiles mecanismos de inspiración totalitaria. En todo caso, la asunción del término por el PCI, aunque adaptado a sus necesidades estratégicas, representa un gesto de independencia inaudito respecto al bloque soviético, que simplemente lo borró de su vocabulario por considerarlo un cuerpo extraño perteneciente al lenguaje del enemigo.

Que el fascismo, a diferencia del nazismo alemán, se jactara de su condición totalitaria resulta tan insólito como que el comunismo italiano se erigiera, desde fecha muy temprana, en adversario del totalitarismo, identificado primero con el fascismo y luego con la Democracia Cristiana. Totalitario era «el otro». Solo en una fecha tardía — sin duda demasiado tardía- empezó a denunciar como tal la política practicada por los gobiernos del Este de Europa. El PCI —se lamentó Occhetto en 1990- había «esperado demasiado tiempo para llamar a aquellos países con su propio nombre: regímenes totalitarios» (Occhetto, 1990). La hora de los eufemismos había pasado para siempre.

Gráfico 1. Uso de «totalitariola»y «totalitarismo» en los debates parlamentarios (número de casos por legislatura)

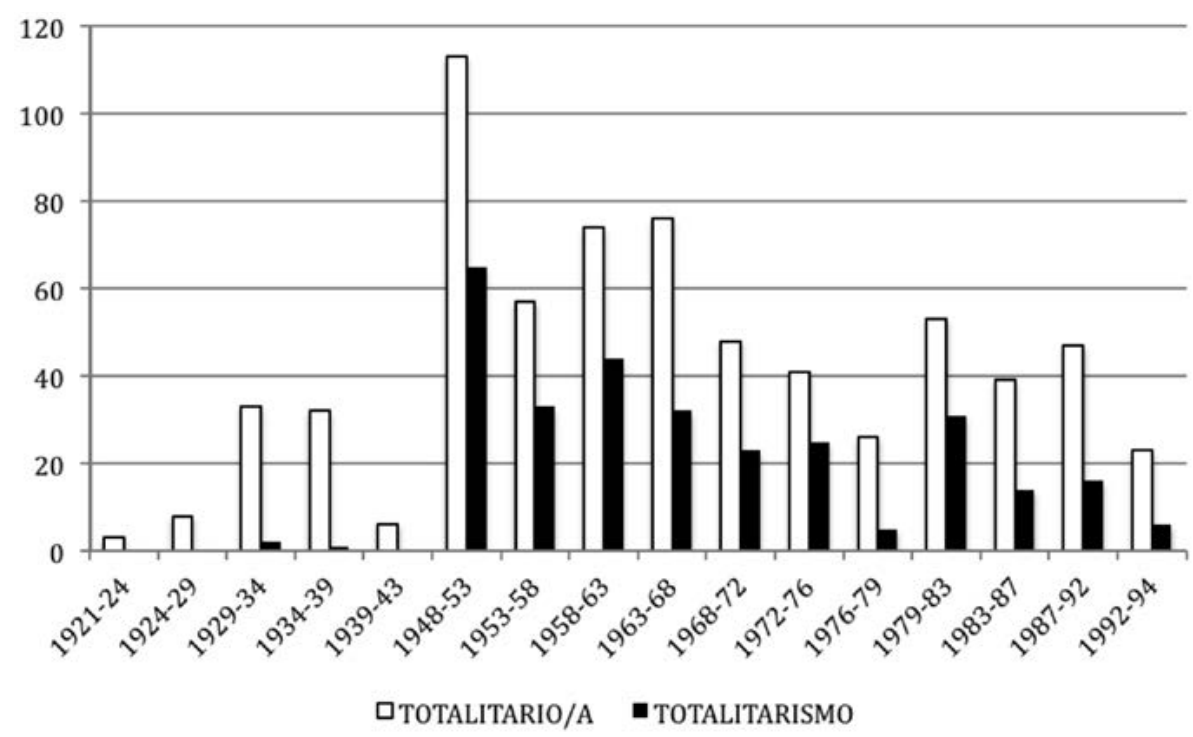

Fuente: Elaboración propia a partir de los datos ofrecidos por el buscador Camera dei deputati: Portale storico (http://storia.camera.it/\#nav). 
GRÁfICO 2. Uso de "totalitario», "totalitaria» $y$ «totalitarismo» en italiano

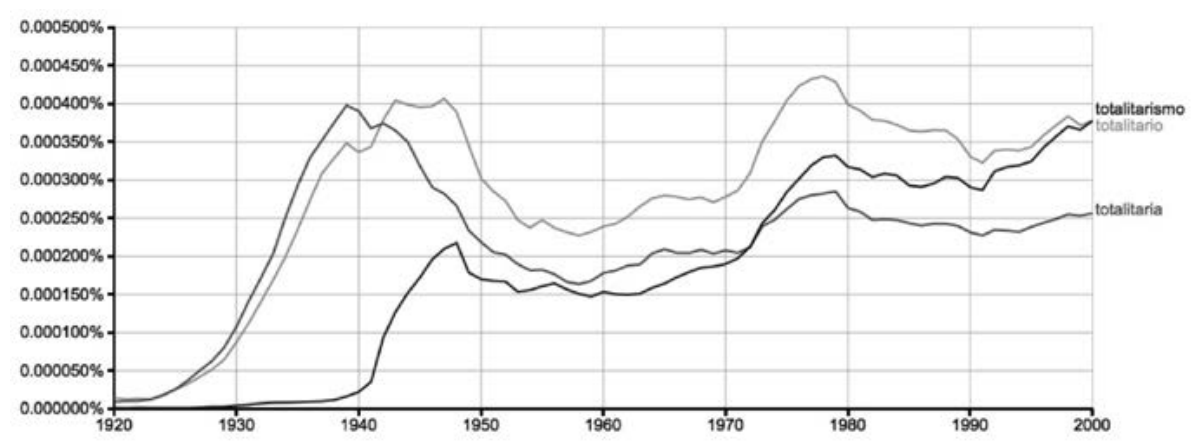

Fuente: Google Ngram Viewer (https://books.google.com/ngrams).

Gráfico 3. La voz «totalitarismo» en el periódico comunista L’Unità

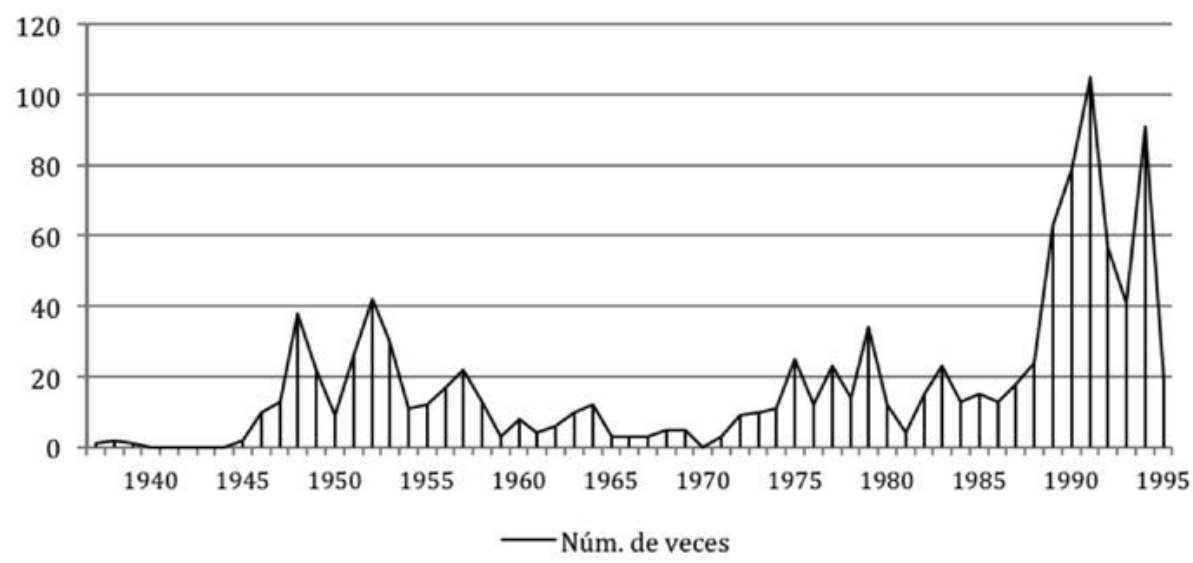

Fuente: Elaboración propia a partir del archivo digital de L'Unità (http://archivio.unita.it/ index.php).

\section{Bibliografía}

Amendola, G. (1923). Maggioranza e minoranza. La Rivoluzione Liberale, 12-5-1923.

AAPP (Atti parlamentari). Camera dei Deputati. Portale storico. Disponible en http://storia. camera.it/\#nav.

Barca, L. (2005). Cronache dallinterno del vertice del PCI. Soveria Mannelli (CZ): Rubbettino Editore. 
Basso, L. (1951). Due totalitarismi: fascismo e democrazia cristiana. Milán: Garzanti.

Berlinguer, E. (1979). Per il socialismo nella pace e nella democrazia in Italia e in Europa. Roma: Editori Riuniti.

_- (1982). L'«alternanza» utiliza la discriminazione del PCI. L'Unità, 15-4-1982.

(1997a). La cuestión comunista. Barcelona: Fontamara.

- (1997b). Gobierno de unidad democrática y compromiso histórico: discursos 1969-1976. Madrid: Ed. Ayuso.

Bertolissi, S. (ed.) (1978). Momenti e problemi della storia dell'URSS. Roma: Editori Riuniti-Istituto Gramsci.

Craxi, B. (1978). Il Vangelo socialista. L'Espresso, 27-8-1978.

Daudet, L. (1918). La guerre totale. París: Nouvelle Librairie Nationale.

De Gaspari, A. (1933-1938). Scritti di politica internazionale, vol. 2. Ciudad del Vaticano: Librería Editrice Vaticana.

De Giovanni, B. (1991). Gli interventi della tribuna di Rimini. L'Unità, 2-2-1991.

Del Noce, A. (1978). Futuro prossimo? Bologna: Edizione Cappelli.

Falasca-Zamponi, S. (1997). Fascist Spectacle. The Aesthetics of Power in Mussolini's Italy. Berkeley-Los Ángeles-Londres: University of California Press.

Fanfani, A. (1974). Contrario al totalitarismo fascista, ma anche al totalitarismo collettivista. La Stampa, 19-7-1974.

Faye, J. P. (1974). Los lenguajes totalitarios. Madrid: Taurus.

Filodemo, P. [L. Basso]. L'antistato. La Rivoluzione Liberale, 2-1-1925.

Fuentes, J. F. (2006). Totalitarismo: Origen y evolución de un concepto clave. Revista de Estudios Políticos, 134, 195-218.

Galli, G. (2008). Mussolini: Il destino a Milano. Milano: Kaos Ed.

Ingrao, P. (1949). Verso il totalitarismo clericale. Rinascista. Anno VI.

Montanari, M. ed. (2004). F. Neumann, A. Gramsci, H. Arendt. Per la critica dei totalitarismi. Antologia di scritti. Lecce: Pensa.

Napolitano, G. (1983). Come avviare una ricerca comune per l'alternativa. L'Unità, 14-09-83.

Occhetto, A. (1990). Sinistra oltre le vecchie barriere. L'Unità, 8-2-1990.

- (2013). La gioiosa macchina da guerra. Roma: Editori Riuniti.

Pasquino, G. (1995). La politica italiana. Dizionario critico 1945-1995. Bari: Editori Laterza.

Petersen, J. (2004). The History of the Concept of Totalitarianism in Italy. En Maier (ed.). Totalitarianism and Political Religions: Concepts for the Comparisons of the Dictatorships (pp. 3-21). Nueva York: Routledge.

Pouthier, J. L. (1989). Luigi Sturzo et la critique de l'État totalitaire. Vingtième Siècle, 21, 83-90.

Siegel, A. (ed.) (1998). The Totalitarian Paradigm after the End of Communism. Towards a Theoretical Reassessment. Amsterdam-Atlanta: Editions Rodopi.

Spadafora, A. (ed.) (1978). Eurocomunismo: sfida all'Europa. Bellinzona: Casagrande.

Sturzo, L. (1924). Spirito e Realtà. La Rivoluzione Liberale, 22-1-1924.

- (1935). El Estado totalitario. Cruz y Raya, 28, 7-39.

Tatò, A. (1985). Conversazioni con Berlinguer. Roma: Editori Riuniti. 
Todorov, T. (2002). Memoria del mal, tentación del bien. Indagación sobre el siglo XX. Barcelona: Península.

Traverso, E. (ed.) (2001). Le totalitarisme: Le XXe siècle en débat. París: Du Seuil.

Valentini, C. (2014). Enrico Berlinguer. Milán: Feltrinelli.

Wall, B. (1952). Reseña del libro de L. Basso Due totalitarismi: Fascismo e democrazia cristiana. International Affairs, 28, 1. Disponible en: http://dx.doi.org/10.2307/2605042 